\title{
Physiological and biochemical effects of triclocarban stress on freshwater algae
}

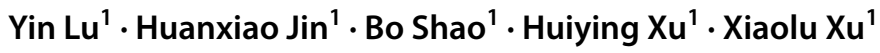

Received: 20 September 2019 / Accepted: 8 November 2019 / Published online: 26 November 2019

(c) Springer Nature Switzerland AG 2019

\begin{abstract}
Triclocarban (TCC) is considered as a contaminant of emerging concern (CEC) and ranked in the top 10 CEC occurrence. TCC is a high-production-volume synthetic chemical used extensively in various personal care products. The heavy use and emission of TCC pose a serious threat to the environment. To evaluate its ecotoxicity, three freshwater algae were exposed to TCC at concentrations ranging from 0.500 to $16,000 \mathrm{mg} / \mathrm{L}$ to determine its growth inhibitory effects. Chlorophyll, malondialdehyde (MDA), antioxidant enzyme activities, and other indicators were used to analyze the mechanism underlying the toxic effect of TCC. With the $96-\mathrm{h}$ median effective concentrations $\left(\mathrm{EC}_{50}\right.$ ) of TCC ranging from 5.445 to $10.220 \mathrm{mg} / \mathrm{L}$, the three types of algae exhibited obvious toxic responses, of which Chlorella vulgaris was the most sensitive. The calculated $96-\mathrm{h} \mathrm{EC}{ }_{50}$ values of TCC were $8.474 \mathrm{mg} / \mathrm{L}, 9.100 \mathrm{mg} / \mathrm{L}$, and $8.760 \mathrm{mg} / \mathrm{L}$ for C. vulgaris, Scenedesmus obliquus, and Chlorella pyrenoidosa, respectively. TCC decreased the chlorophyll content, increased the MDA content, decreased the peroxidase activity, and decreased superoxide dismutase activity in the three algae, indicating that the chemical can inhibit photosynthesis and destroy the activities of antioxidant enzymes in algae. Most of the indicators showed a positive correlation with the concentration of TCC.
\end{abstract}

Keywords Triclocarban · Green algae $\cdot$ Chlorophyll · Peroxidase · Superoxide dismutase

\section{Introduction}

The antimicrobial agents triclocarban (3,4,4'-trichlorocarbanilide; TCC) is high-production-volume chemicals that are widely used in a variety of personal care products (PCPs) [1]. Its mass production and daily application have continued for more than 30 years, and a conservative estimate indicates that the world's largest annual usage is over $750 \times 10^{3} \mathrm{t}[2]$. Currently, TCC is among the top 10 most commonly detected organic wastewater compounds for frequency and concentration in the whole world [3]. It has been detected in wastewater effluent in quantities up to micromolar concentrations ( $\mu \mathrm{g} / \mathrm{L}$ ) in Asia, Europe, and North America, indicating widespread environmental contamination. This substance is highly lipophilic, can accumulate in various organisms, has been used for a long time, and poses potential threats to the environment and organisms. Although the detection of the instrument can quantify TCC concentration, it cannot measure directly the influences on test organisms. Due to the persistence and toxicity of TCC, its aquatic ecotoxicity has attracted wide attention [4]. In recent years, its toxic effects, such as inhibitory effects on growth and development, endocrine disruption, and reproductive toxicity, have caused great concerns [5-11]. Several studies provided evidence that TCC interferes with biological receptors in vitro, including a stably transfected aryl hydrocarbon receptor (AhR)-, androgen receptor (AR)-, or estrogen receptor (ER)responsive firefly luciferase reporter gene that responds to chemicals that can bind to and/or activate the respective receptor [12]. Moreover, TCC could also be a significant

Xiaolu Xu, 58435593@qq.com | 'College of Biology and Environmental Engineering, Zhejiang Shuren University, Hangzhou, China. 
concern when it coexists with TCS, whose hazard quotient was reported to be over 10 by Brausch and Rand [13].

Algae are at the bottom of the food chain in aquatic ecosystems. These organisms are sensitive to environmental pollution and are also an important segment in the accumulation of toxic substances, which can advance to consumers through the food chain. They are routinely employed as test organisms for ecotoxicological studies. Normally, the molecular, cellular, and physiological levels of algae change dramatically when they are under contamination stress. The examination of 139 water sources in 30 US states by the US Geological Survey [14] and that of the Zhujiang River, Yangtze River, Yellow River, and other water systems in China indicated that TCC was a highly accumulated pollutant. The maximum detected concentration in water is $338 \mathrm{ng} / \mathrm{L}$ that in the sediment reaches $2.723 \mu \mathrm{g} / \mathrm{g}$, and the concentrations in water samples from wastewater treatment plants are as high as $0.4-50 \mu \mathrm{g} / \mathrm{L}$ [14-16]. TCC can also be detected in organisms, at levels ranging from 50 to $400 \mu \mathrm{g} / \mathrm{kg}$ in Cladophora, 50-300 $\mu \mathrm{g} /$ $\mathrm{kg}$ in freshwater snail, $14,000-80,000 \mu \mathrm{g} / \mathrm{kg}$ in bream bile, $0.75-10 \mu \mathrm{g} / \mathrm{kg}$ in pelagic fish plasma, $9.0 \mu \mathrm{g} / \mathrm{kg}$ in killer whale plasma, $0.4-38.0 \mathrm{ng} / \mathrm{g}$ in the plasma of lactating mothers, and $0.022-0.95 \mathrm{ng} / \mathrm{g}$ in the breast milk $[17,18]$. Therefore, the ecological toxicity of TCC requires attention.

This study aimed to treat three typical freshwater algae with different concentrations of TCC and then analyze the growth inhibition, photosynthesis, and antioxidant capacity of algae to evaluate the possible toxic effect of TCC on algae and its underlying mechanism to lay a foundation for the control of environmental pollution by TCC and for biological toxicology research.

\section{Materials and methods}

\subsection{Chemicals}

The TCC standard was obtained from J\&K Scientific Ltd (Beijing, China) with a purity of $97 \%$. The HPLC-grade reagents including methanol, acetonitrile, ethyl acetate, hexane, dichloromethane, formic acid, and acetic acid were supplied by Merck (Germany), CNW Technologies (China), and Tedia (USA). Glass fiber filters (GF/F, pore size $0.7 \mu \mathrm{m}$ ) were obtained from Whatman (Maidstone, UK). Oasis HLB cartridges (200 mg, $6 \mathrm{~mL}$ ) were from Waters (Milford, USA). HPLC-grade water was from a Milli-Q water purification system (Millipore, Watford).

\subsection{Test organisms}

To create a representative subtropical community, we used three species of algae: Chlorella vulgaris, Scenedesmus obliquus, and Chlorella pyrenoidosa, which were provided by the Institute of Hydrobiology, Chinese Academy of Sciences. The algae were laboratory cultured in BG11 medium at $23 \pm 1{ }^{\circ} \mathrm{C}$ and a light intensity of 4000 lux(provided by $40 \mathrm{~W}$ white fluorescent lamps, Philips F40 T12/DX) with a dark/light cycle of $14 \mathrm{~h} / 10 \mathrm{~h}$. The preparation of BG11 medium can be found in a previous study [19]. The biomass was measured by microscopic counting and optical density (OD) at $690 \mathrm{~nm}$ at 24-h intervals during $120 \mathrm{~h}$ of culture. Growth curves were plotted to establish the relationship between the cell density and $\mathrm{OD}_{690}$ values for the different algae using a linear regression equation.

\subsection{Toxic test of TCC on algae}

\subsubsection{Exposure strategies}

In the exposure experiment, the algae at the logarithmic growth phase were collected, washed, and then diluted by freshwater to the initial concentration of $2 \times 10^{5}$ cells $\mathrm{mL}^{-1}$. The three species of algae were cultured with the final concentrations of TCC of $0.5,1,2,4,8$, and $16 \mathrm{mg} / \mathrm{L}$. After $96 \mathrm{~h}$ of culture, the biomass, chlorophyll, malondialdehyde (MDA), peroxidase (POD), superoxide dismutase (SOD), and other indicators were measured to evaluate the corresponding toxic effects, with the biomass analyzed once every $24 \mathrm{~h}$ [20]. Three replicates were set for each concentration group.

\subsubsection{Growth inhibition of algae and calculation of the 96-h median effective concentration ( $\mathrm{EC}_{50}$ )}

OD was measured every $24 \mathrm{~h}$ of exposure, and algal growth curves were generated based on OD values. After establishing the linear regression relationship between the inhibition rate $(P \%)$ and the natural logarithm of the concentration, the concentration value of $50 \%\left(\mathrm{EC}_{50}\right)$ was determined. The inhibition ratio was calculated as follows:

$P(\%)=\left(\right.$ control $\mathrm{OD}_{690}-$ treated group $\left.\mathrm{OD}_{690}\right) /$ control $\mathrm{OD}_{690}$.

\subsubsection{Determination of the chlorophyll content in algae}

The algae were collected and filtered through a microporous membrane, and $7 \mathrm{~mL}$ of ethanol was added. The contents of the flask were transferred to a centrifuge tube, and the volume was adjusted to $10 \mathrm{~mL}$. The biomass was extracted in the dark at $4{ }^{\circ} \mathrm{C}$ for $4 \mathrm{~h}$, and the extract was centrifuged at $3000 \mathrm{rpm}$ for $20 \mathrm{~min}$. The supernatant was transferred to a colorimetric tube, and the volume was adjusted to $10 \mathrm{~mL}$ by adding $90 \%$ ethanol. OD values of 
the supernatants were measured in a 1-cm cuvette, and the chlorophyll- $a$ concentration was calculated as follows:

$$
\begin{aligned}
& \text { Chlorophyll }-a(\mathrm{mg} / \mathrm{L})=\left(11.64 \mathrm{~A}_{633}\right. \\
& \left.+2.16 \mathrm{~A}_{645}+0.10 \mathrm{~A}_{630}\right) V_{1} / 1000 V_{2}
\end{aligned}
$$

where $V_{1}$ is the volume of the extract $(\mathrm{mL})$ and $V_{2}$ is the volume of the filtrate $(\mathrm{L})$.

\subsubsection{Determination of the algal MDA content}

The algal fluid was filtered through a membrane and then mixed with $10 \%$ tricarboxylic acid. The homogenate was centrifuged at $12,000 \mathrm{rpm}$ for $10 \mathrm{~min}$ to collect the supernatant as the MDA extract, of which $2 \mathrm{~mL}$ was transferred to a test tube, mixed with $2 \mathrm{~mL}$ of $0.6 \%$ thiobarbituric acid, and heated in a boiling water bath for $10 \mathrm{~min}$. After centrifugation at $4500 \mathrm{rpm}$ for $10 \mathrm{~min}$, OD of the supernatant was measured, and the MDA concentration was calculated as follows:

MDA concentration $=6.45\left(A_{532}-A_{600}\right)-0.56 \times A_{450}$.

\subsubsection{Determination of algal SOD and POD activities}

SOD activity was assayed at $560 \mathrm{~nm}$ by the nitro-bluetetrazolium (NBT) photoreduction method [21]. One unit of SOD activity was defined as the amount of enzyme required to cause $50 \%$ inhibition of the reduction in NBT as monitored at $560 \mathrm{~nm}$ by a spectrophotometer (722type, Shanghai Instrument Factory, China). Scavenging of $\mathrm{O}_{2}{ }^{-}$by SOD prevents the accumulation of intermediates, which is used for the determination of the enzyme activity. POD activity was determined at $470 \mathrm{~nm}$ using the guaiacol method [22]. The reaction mixture $(3 \mathrm{~mL})$ contained $50 \mathrm{mM}$ PBS (Ph 5.5), $20 \mathrm{mM}$ guaiacol, $1 \mathrm{~mL} 30 \%(\mathrm{w} / \mathrm{v}) \mathrm{H}_{2} \mathrm{O}_{2}$, and $0.1 \mathrm{~mL}$ enzyme extract.

\subsection{Statistical methods}

All experiments were performed at least in triplicate. The quantitative data were expressed as mean and standard deviation/standard error. If the homoscedasticity assumptions of the data were satisfied, least significant difference (LSD) tests were further conducted to analyze the statistical significance among individual treatments using SPSS V25 (IBM, Armonk, NK, USA). $P<0.05$ was considered statistically significant, and $P<0.01$ was considered highly significant.

\section{Results}

\subsection{Establishment of a spectrophotometric method for algal biomass}

As shown in Fig. 1, there was a good linear relationship between the biomass and OD values for the three algae. The regression equations established for the three algae were as follows: $C$. pyrenoidosa: $y=0.0164 x-0.0299$ $\left(R^{2}=0.9905\right) ; C$. vulgaris: $y=0.0172 x-0.04\left(R^{2}=0.9894\right) ;$ and S. obliquus: $y=0.0168 x-0.0271\left(R^{2}=0.9966\right)$.

\subsection{Inhibitory effects of TCC on the growth of the three species of algae}

The rates of algal growth inhibition by TCC were shown in Fig. 2. Within the test range, the inhibition rates of the three algae by TCC all showed a positive correlation with the TCC concentrations; the calculated $96-\mathrm{h} \mathrm{EC}_{50}$ value of TCC for C. vulgaris was $8.474 \mathrm{mg} / \mathrm{L}$, that for S. obliquus was $9.11 \mathrm{mg} / \mathrm{L}$, and that for C. pyrenoidosa was $8.76 \mathrm{mg} / \mathrm{L}$. Among the three species of algae, $C$. vulgaris was the most sensitive to TCC.
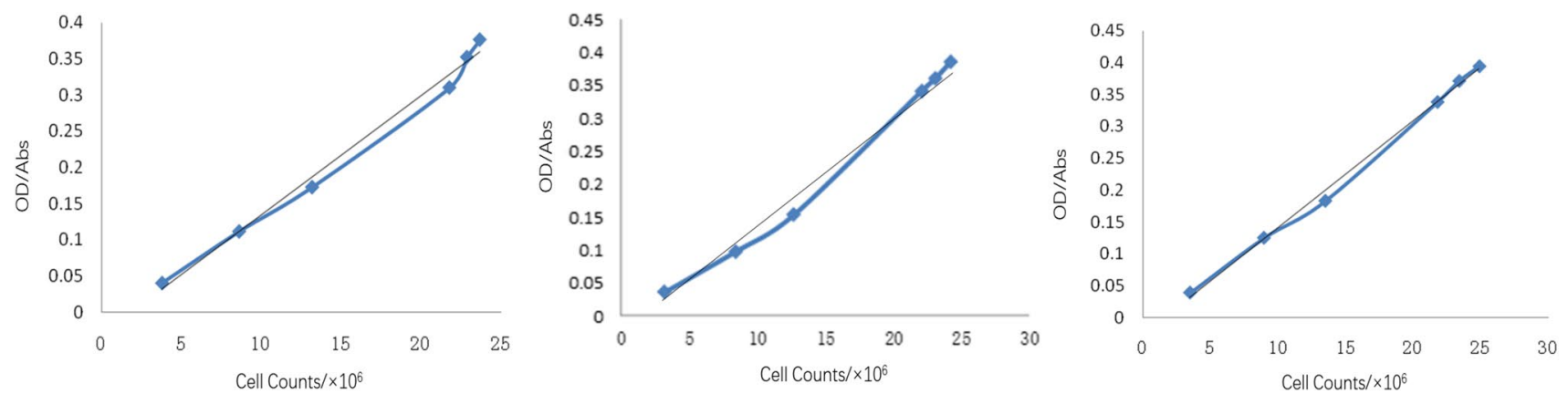

Fig. 1 Relationship between the biomass and OD values for the three algae (left: C. pyrenoidosa; middle: C. vulgaris; right: S. obliquus) 

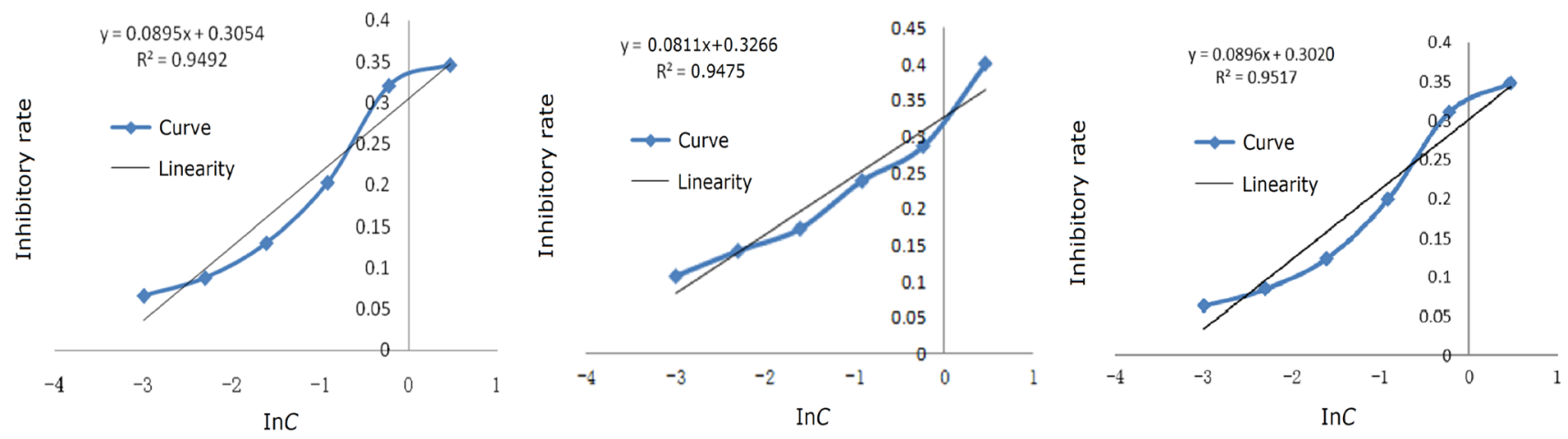

Fig. 2 Inhibitory curves of different concentrations of TCC for the three algae (left: C. pyrenoidosa; middle: C. vulgaris; right: S. obliquus)

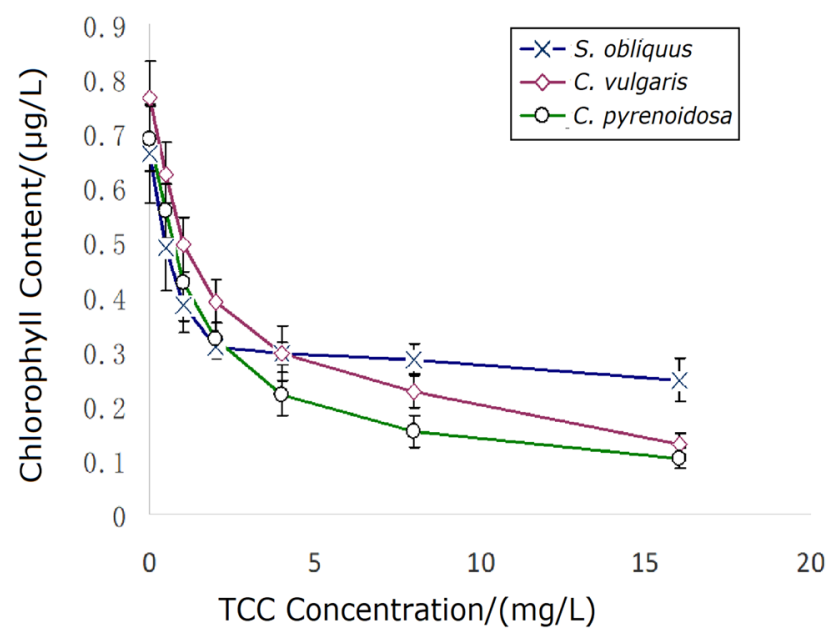

Fig. 3 Effects of different concentrations of TCC on the chlorophyll content in the three algae

\subsection{Effects of TCC on the chlorophyll content in the three algae}

TCC caused significant decreases in the chlorophyll- $a$ content in the three algae (shown in Fig. 3), and the extent of the decrease was positively correlated with the exposure concentration. The decreases in the chlorophyll- $a$ content were stronger than those in biomass, indicating that they were caused not only by the decreases in biomass but also by a targeted toxic effect of TCC on the photosynthesis in algae. Among the three algae, $S$. obliquus showed the best TCC tolerance and C. pyrenoidosa was the most sensitive.

\subsection{Effects of TCC on the MDA content in the three algae}

TCC exposure elevated the MDA levels in all three algae, indicating the occurrence of stress (shown in Fig. 4). Except that in C. vulgaris, the MDA level was basically positively

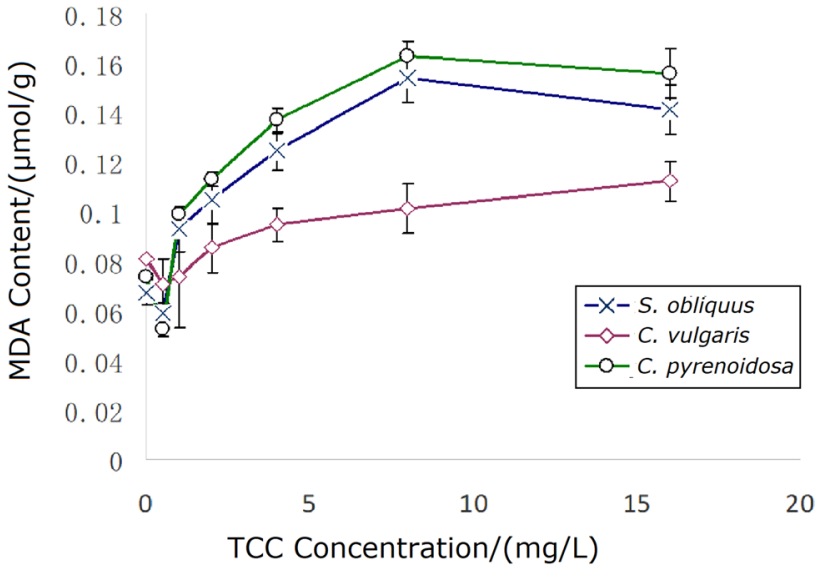

Fig. 4 Effects of different concentrations of TCC on the MDA content in the three algae

correlated with the TCC concentration. The highest effect was caused not by the highest concentration but was observed at $8 \mathrm{mg} / \mathrm{L} \mathrm{TCC}$, showing that the stress resistance in algae is complicated.

MDA is the final decomposition product of membrane lipid peroxidation, and its content reflects the degree of stress damage to algae. The TCC concentrations in the range tested in this study caused an increase in the MDA content, indicating that the algae experienced stress, leading to cell membrane damage and increased cell membrane permeability. Using the TCC effect on S. obliquus as an example, the MDA content in the control group was of $0.068 \mu \mathrm{mol} / \mathrm{g}$, and that in the treated groups was 0.060 , $0.093,0.105,0.125,0.154$, and $0.141 \mu \mathrm{mol} / \mathrm{g}$, which was up to 2.35 times of that in the control group.

\section{SN Applied Sciences}




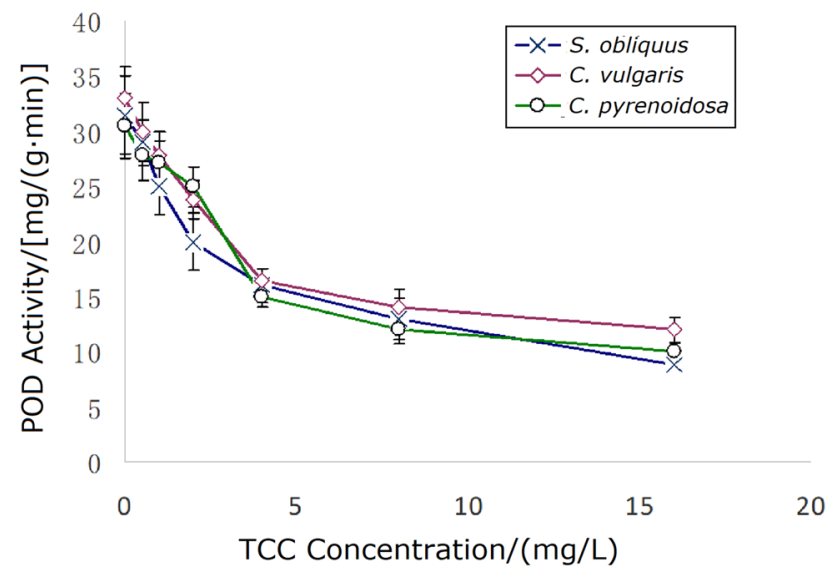

Fig. 5 Effects of different concentrations of TCC on the POD activity in the three algae

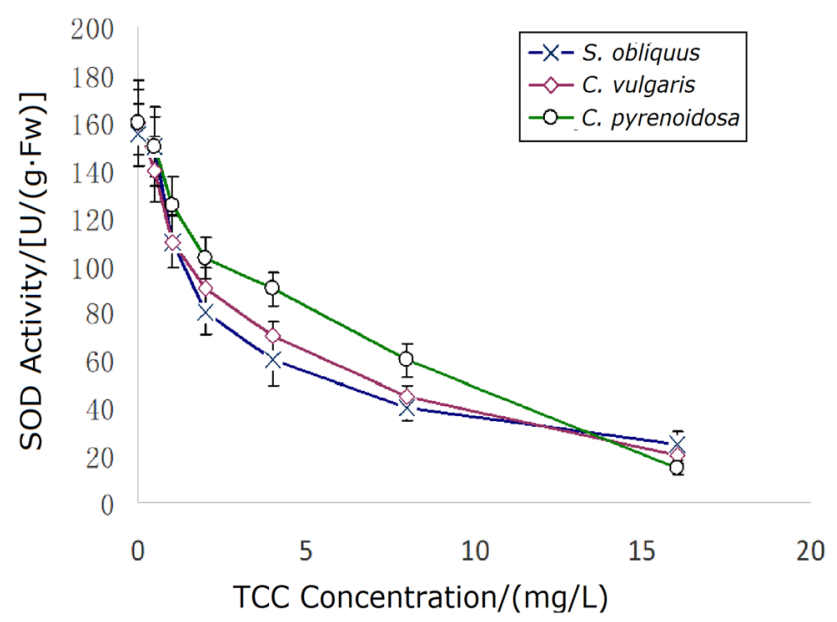

Fig. 6 Effects of different concentrations of TCC on the SOD activity in the three algae

\subsection{Effects of TCC on the POD activity in the three algae}

As shown in Fig. 5, TCC caused significant decreases in the POD activity in the three algae, and the degree of inhibition was positively correlated with the TCC concentration. The differences among the three algae were not significant, and their sensitivities were relatively similar.

\subsection{Effects of TCC on the SOD activity in the three algae}

TCC caused significant decreases in the SOD activity in the three algae (shown in Fig. 6), and the degree of inhibition was positively correlated with the TCC concentration. The maximum TCC concentration reduced the SOD activity to approximately $1 / 4$ of the normal level, indicating significant damage to SOD activity by TCC.

POD is the enzyme responsible for the decomposition of peroxides, while SOD is the enzyme responsible for scavenging oxygen free radicals, and both are key enzymes allowing algae to resist oxidative damage and remove metabolic wastes, which is very important for the growth and metabolism of algae. TCC was shown to significantly damage both activities. Taking the effect of TCC on the POD activity in C. pyrenoidosa as an example, the activity in the control group was $32 \mathrm{mg} / \mathrm{g} / \mathrm{min}$ and that in the exposed groups was $29,25,20,16,13$, and $9 \mathrm{mg} / \mathrm{g} /$ $\mathrm{min}$. The lowest activity in the exposed groups was $28.13 \%$ of that in the control group. Taking the effect of TCC on the SOD activity in C. pyrenoidosa as an example, the activity in the control group was $178 \mathrm{U} / \mathrm{g}$.fresh weight $(\mathrm{Fw})$ and that in the exposed groups was $160,143,118,88,56$, and $27 \mathrm{U} / \mathrm{g} \mathrm{Fw}$. The lowest activity in the exposed groups was $15.17 \%$ of that in the control group.

\section{Discussion}

The effects of TCC differed among the organisms that were introduced to the microcosms. In these microcosms, both phytoplanktonic and periphytonic chlorophyll-a content decreased as the concentrations of TCC in the sediment increased. Algae are known to be particularly sensitive to TCC, with growth inhibition typically being recorded at $\mathrm{EC}_{50}$ values of $0.53 \mu \mathrm{g} / \mathrm{L}-430 \mu \mathrm{g} / \mathrm{L}$, depending on the test conditions and species [23, 24]. In this study, TCC caused a significant decrease in the chlorophyll content in the algae. The 96-h EC ${ }_{50}$ values of TCC for C. pyrenoidosa, C. vulgaris, and S. obliquus were between 5.445 and $10.22 \mathrm{mg} / \mathrm{L}$. Although the TCC content in most of the current water systems has not yet reached the $96-\mathrm{h} \mathrm{EC}_{50}$ values for the algae, the lowest-concentration groups of the algae $(0.5 \mathrm{mg} / \mathrm{L})$ also showed some toxicity effects, indicating that the monitoring and control of TCC should be strengthened.

Among the indexes analyzed in this study, chlorophyll was the executor of photosynthesis, and its content directly reflects the growth and reproduction ability of algae. Taking the effect of TCC on C. vulgaris as an example, the concentration of chlorophyll- $a$ in the control group was $0.764 \mu \mathrm{g} / \mathrm{L}$, while that in each group was $0.623,0.496$, $0.391,0.295,0.227$, and $0.130 \mu \mathrm{g} / \mathrm{L}$, respectively. The lowest group was only $20.86 \%$ of that in the control group, the effect was very obvious, and the experiment of other algae showed similar characteristics.

TCC and its transformation products (4,4'-dichlorocarbilide (DCC), 1-(3-chlorophenyl)-3-phenylurea (MCC) and carbanilide (NCC), $2^{\prime} \mathrm{OH}-\mathrm{TCC}, 3^{\prime} \mathrm{OH}-\mathrm{TCC}$ ) were detected in 
the environmental matrices. TCC is an antimicrobial agent and also emerging endocrine disruptor that can cause immune dysfunction and affect human reproductive outcomes. Furthermore, TCC alters the expression of proteins related to binding and metabolism, skeletal muscle development and function, and nervous system development and immune response. TCC has potential health risks in wild life and humans. Several animal studies illustrate that it can cause various adverse effects, which can be monitored by antioxidant biomarkers (CAT, GST, and LPO) [25]. The first mechanism is a possible increase in intracellular oxidative stress, which could arise from a pathological increase in the production of oxyradicals (mainly $\mathrm{H}_{2} \mathrm{O}_{2}$, which is produced in mitochondria by dismutation of $\mathrm{O}_{2}^{-}$) through the cellular mitochondrial enzymatic complex chain [26]. Alternatively, TCC may act together as a DNA adduct and/or DNA intercalant to directly exert genotoxic effects [27].

Numerous uncertainties remain including the evaluation of antioxidant enzymes, the possible interference with hormone metabolism, and the role played by the metabolites of TCC. It is necessary to fully understand the biological toxic effect of TCC on this sentinel organism. As these questions continue to be addressed, more definitive and comprehensive aquatic risk assessments should be developed to raise greater public awareness about the potential risk of TCC released into aquatic environments.

\section{Conclusions}

TCC showed a significant acute toxicity to the freshwater algae, significantly inhibiting their growth, destroying their photosynthetic ability, and impairing their antioxidant function. Because this study was a short-term exposure study, taking into account a long-term cumulative effect of TCC in the environment, it is necessary that TCC should be listed as an important environmental pollutant of great concern, and its content should be tested in each major river system. Furthermore, this paper provides the basic information regarding the physiological and biochemical effects of TCC stress on freshwater alga, and further systematic toxicology research should be carried out on model organisms at all levels to understand toxicity mechanisms.

Acknowledgements The authors of this study express their gratitude to the National Natural Science Foundation of China (31600257) and Public welfare project of Zhejiang provincial Science and Technology Department (2016C32022) for financial support of this study.

\section{Compliance with ethical standards}

Conflict of interest The authors declare that they have no conflict of interest.

\section{References}

1. Prakash D, Kumar S, Tomar N (2016) Uses of peroxide on the formation of chlorinated phenolics by gas chromatography technique in nonwood pulps to reduce toxicity in paper manufacturing. Int Conf Condens Matter Appl Phys 1728(1):020094

2. Semblante GU, Hai Fl, McDonald J, Khan SJ, Nelson M, Lee DJ, Price WE, Nghiem LD (2017) Fate of trace organic contaminants in oxic-settling-anoxic (OSA) process applied for biosolids reduction during wastewater treatment. Bioresour Technol 240:181-191

3. Lu J, Mao H, Li H, Wang Q, Yang Z (2017) Occurrence of and human exposure to parabens, benzophenones, benzotriazoles, triclosan and triclocarban in outdoor swimming pool water in Changsha, China. Sci Total Environ 605-606:1064-1069

4. Ebele AJ, Abdallah MAE, Harrad S (2017) Pharmaceuticals and personal care products (PPCPs) in the freshwater aquatic environment. Emerg Contam 3(1):1-16

5. Horie Y, Yamagishi T, Takahashi H, Iguchi T, Tatarazako N (2018) Effects of triclosan on Japanese medaka (Oryzias latipes) during embryo development, early life stage and reproduction. J Appl Toxicol 38(4):544-551

6. Halden RU (2016) Lessons learned from probing for impacts of triclosan and triclocarban on human microbiomes. Sphere 1(3):e00089-16

7. Dwivedi $A D$, Dubey SP, Sillanpää $M$, Kwon $Y N$, Lee $C$, Varma RS (2015) Fate of engineered nanoparticles: implications in the environment. Coord Chem Rev 287:64-78

8. Martins D, Monteiro MS, Soares AM, Quintaneiro C (2017) Effects of 4-MBC and triclosan in embryos of the frog Pelophylax perezi. Chemosphere 178:325-332

9. Lin D, Li Y, Zhou QX, Wang D (2014) Effect of triclosan on reproduction, DNA damage and heat shock protein gene expression of the earthworm Eisenia fetida. Ecotoxicology 23(10):1826-1832

10. O'Brien JW, Banks AP, Novic AJ, Mueller JF, Jiang G, Ort C, Eaglesham G, Yuan Z, Thai PK (2017) Impact of in-sewer degradation of pharmaceutical and personal care products (PPCPs) population markers on a population model. Environ Sci Technol 51(7):3816-3823

11. Kim BR, Bae YM, Lee SY (2016) Effect of environmental conditions on biofilm formation and related characteristics of staphylococcus aureus. J Food Saf 36(3):412-422

12. Vingskes AK, Spann N (2018) The toxicity of a mixture of two antiseptics, triclosan and triclocarban, on reproduction and growth of the nematode Caenorhabditis elegans. Ecotoxicology 27(4):420-429

13. Brausch JM, Rand GM (2011) A review of personal care products in the aquatic environment: environmental concentrations and toxicity. Chemosphere 82(11):1518-1532

14. Zhang QQ, Ying GG, Chen ZF, Zhao JL, Liu YS (2015) Basin-scale emission and multimedia fate of triclosan in whole China. Environ Sci Pollut Res Int 22(13):10130-10143

15. Chen ZF, Wen HB, Dai X, Yan SC, Zhang H, Chen YY, Du Z, Liu G, Cai $Z$ (2018) Contamination and risk profiles of triclosan and triclocarban in sediments from a less urbanized region in China. J Hazard Mater 357:376-383 
16. Zhao JL, Zhang QQ, Chen F, Wang L, Ying GG, Liu YS, Yang B, Zhou LJ, Liu S, Su HC, Zhang RQ (2013) Evaluation of triclosan and triclocarban at river basin scale using monitoring and modeling tools: implications for controlling of urban domestic sewage discharge. Water Res 47(1):395-405

17. Wijnen JV, Ragas AMJ, Kroeze C (2018) River export of triclosan from land to sea: a global modelling approach. Sci Total Environ 621:1280-1288

18. González-Pleiter $M$, Rioboo $C$, Reguera $M$, Abreu I, Leganés $F$, Cid Á, Fernández-Piñas F (2017) Calcium mediates the cellular response of Chlamydomonas reinhardtii to the emerging aquatic pollutant Triclosan. Aquat Toxicol 186:50-66

19. Rippka R, Deruelles J, Waterbury JB, Herdman M, Stanier RY (1979) Generic assignments, strain histories and properties of pure cultures of cyanobacteria. Microbiology 111(1):1-61

20. Ding T, Lin K, Bao L, Yang M, Li J, Yang B, Gan J (2018) Biouptake, toxicity and biotransformation of triclosan in diatom Cymbella sp. And the influence of humic acid. Environ Pollut 234(2018):231-242

21. Liang YC, Zhu J, Li ZJ, Chu GX, Ding YF, Zhang J, Sun WC (2008) Role of silicon in enhancing resistance to freezing stress in two contrasting winter wheat cultivars. Environ Exp Bot 64:286-294

22. Xu LL, Ye MB (1989) A measurement of peroxidase activity using continuous recording method. J Naning Agric Univ 12(3):82-83 (in Chinese)
23. Orvos DR, Versteeg DJ, Inauen J, Capdevielle $M$, Rothenstein A, Cunningham V (2002) Aquatic toxicity of triclosan. Environ Toxicol Chem 21:1338-1349

24. Yang LH, Ying GG, Su HC, Stauber JL, Adams MS, Binet MT (2008) Growth-inhibiting effects of 12 antibacterial agents and their mixtures on the freshwater microalga pseudokirchneriella subcapitata. Environ Toxicol Chem 27:1201-1208

25. Vimalkumar K, Seethappan S, Pugazhendhi A (2019) Fate of Triclocarban (TCC) in aquatic and terrestrial systems and human exposure. Chemosphere 230:201-209

26. Werbin MH, Rocha P, Arpi O, Taus A (2019) Serum cytokine levels as predictive biomarkers of benefit from ipilimumab in small cell lung cancer. Oncoimmunology 8(6):1-9

27. Xu XL, Lu Y, Zhang DY, Wang Y, Zhou XS, Xu HY, Mei Y (2015) Toxic assessment of triclosan and triclocarban on Artemia salina. Bull Environ Contam Toxicol 95(6):728-733

Publisher's Note Springer Nature remains neutral with regard to jurisdictional claims in published maps and institutional affiliations. 